\title{
Parasites of Trinidadian guppies: evidence for sex- and age-specific trait-mediated indirect effects of predators
}

\author{
Jessica F. Stephenson, ${ }^{1,4}$ Cock van Oosterhout, ${ }^{2}$ Ryan S. Mohammed, ${ }^{3}$ and Joanne Cable ${ }^{1}$ \\ ${ }^{1}$ School of Biosciences, Cardiff University, Cardiff CF10 3 AX United Kingdom \\ ${ }^{2}$ School of Environmental Sciences, University of East Anglia, Norwich Research Park, Norwich NR4 7TJ United Kingdom \\ ${ }^{3}$ Department of Life Sciences, University of the West Indies, St. Augustine, Trinidad and Tobago
}

\begin{abstract}
Predation pressure can alter the morphology, physiology, life history, and behavior of prey; each of these in turn can change how surviving prey interact with parasites. These trait-mediated indirect effects may change in direction or intensity during growth or, in sexually dimorphic species, between the sexes. The Trinidadian guppy, Poecilia reticulata presents a unique opportunity to examine these interactions; its behavioral ecology has been intensively studied in wild populations with well-characterized predator faunas. Predation pressure is known to have driven the evolution of many guppy traits; for example, in highpredation sites, females (but not males) tend to shoal, and this anti-predator behavior facilitates parasite transmission. To test for evidence of predator-driven differences in infection in natural populations, we collected 4715 guppies from 62 sites across Trinidad between 2003 and 2009 and screened them for ectosymbionts, including Gyrodactylus. A novel model-averaging analysis revealed that females were more likely to be infected with Gyrodactylus parasites than males, but only in populations with both high predation pressure and high infection prevalence. We propose that the difference in shoaling tendency between the sexes could explain the observed difference in infection prevalence between males and females in high-predation sites. The infection rate of juveniles did not vary with predation regime, probably because juveniles face constant predation pressure from conspecific adults and therefore tend to shoal in both high- and low-predation sites. This represents the first evidence for age- and sex-specific trait-mediated indirect effects of predators on the probability of infection in their prey.
\end{abstract}

Key words: Gyrodactylus; hierarchical spatial analysis; model averaging; Poecilia reticulata; sexbiased parasitism; trait-mediated indirect effects.

\section{INTRODUCTION}

Predators affect the density and traits of their prey, and each of these can have important implications for infectious disease dynamics in prey populations. Density-mediated effects are well-studied (e.g., Anderson and May 1981, Holt and Roy 2007), and make the specific prediction that predators should reduce parasite transmission because predation can reduce prey density, thereby decreasing contact rates among hosts (Packer et al. 2003). However, recent work suggests that traitmediated effects can be at least as important as those mediated by density (Werner and Peacor 2003, Hatcher et al. 2006). Trait-mediated indirect effects arise when a change in the phenotype of individuals of one species, caused by the presence of another, alters how the reacting species interacts with others in the community (Werner and Peacor 2003). Predators affect prey morphology, physiology, life history, and behavior, each of which is likely to change how the prey interacts with its parasites. For example, Daphnia dentifera

Manuscript received 13 March 2014; revised 5 June 2014; accepted 8 July 2014. Corresponding Editor: K. D. Lafferty.

${ }^{4}$ E-mail: jfrstephenson@gmail.com attains a relatively large body size in the presence of chemical cues of an invertebrate predator, and consequently upon death, releases more spores of a virulent yeast parasite (Duffy et al. 2011). Additionally, Parris and Beaudoin (2004) found that fungal pathogens reduce tadpole development rates only when predators are present, and they hypothesized that this is due to the higher level of predator-induced physiological stress. Predators may also evoke behavioral changes: negatively phototactic D. magna clones avoid visually hunting predators, and as a result suffer increased exposure to parasite spores in pond sediment (Decaestecker et al. 2002). Here, we investigated the net effect of predation on disease transmission by comparing parasite prevalence among several wild guppy populations.

The sexes of many species are dimorphic in a variety of traits and it is logical, if unexplored, that traitmediated indirect effects act differently upon males and females. This may be due to intrinsic differences; for example, male crayfish possess larger claws than females and are therefore less vulnerable to predation. Males consequently show a less dramatic behavioral response to the presence of a predator (Stein and Magnuson 1976). Response to parasites is also known to differ 
markedly between the sexes in vertebrates; males have a higher parasite prevalence (the percentage of potential hosts infected, Bush et al. 1997) than females in a wide range of taxa (Zuk and McKean 1996). Reasons for this bias include sex differences in traits that alter exposure or susceptibility to parasites, or both (Zuk and McKean 1996). Predator-driven sex-specific changes in these traits may well contribute to sex-biased parasitism.

Ontogenetic development often leads to dramatic changes in size, morphology, physiology, and habitat use; trait-mediated indirect effects are likely to act differently on individuals as they age (Werner and Peacor 2003). The effects of the presence or cues of predators on various traits have been shown to differ between the size and age classes of a number of species. For example, smaller, more vulnerable tadpoles reduce activity by up to $98 \%$ more than large tadpoles in the presence of a predator (McCoy and Bolker 2008). Predator-driven trait changes may therefore also contribute to ontogenetic differences in parasitism.

Guppies inhabiting the streams of Trinidad provide an unprecedented opportunity to test for the importance of age- and sex-specific trait-mediated indirect effects on parasitism in a natural system. The guppy (Poecilia reticulata) system has been instrumental to our understanding of the role predation plays in shaping the evolution of species (Magurran 2005). Its appeal as a model system stems from the topography of its habitat; waterfalls that represent significant upstream migration barriers, both to guppies and crucially to their predators, bisect these streams, creating several replicated upper- and lower-course populations. It is well-recognized that lower-course populations experience more intense predation pressure than those in upper courses, and that this variation in predation pressure drives sexspecific trait changes (Haskins et al. 1961, Endler 1978, Houde 1997, Reznick et al. 1997, Magurran 2005). Typically, studies investigating the role of predation pressure in driving guppy evolution control for changes in abiotic factors between upper and lower courses such as water chemistry, flow rate, and primary productivity due to canopy cover. Conclusively, these trait differences evolve rapidly during transplant experiments when lower-course-population guppies are introduced into upper courses, or when voracious predators are introduced into upper-course populations (Endler 1980, Reznick et al. 1997, Gordon et al. 2009). Trait changes between upper- and lower-course guppies that have been attributed to predation pressure include body size, male coloration, mate choice behavior, life history, and life expectancy (Haskins et al. 1961, Seghers 1974, Endler 1978, 1980, Reznick et al. 1997; reviewed by Houde 1997, Magurran 2005). Anti-predator behavior is among the most striking of these trait changes; females from lower-course populations show greater shoal cohesion (Seghers 1974, Endler 1978) and spend more time shoaling than those from upper courses (Magurran and Seghers 1994a). Conversely, juvenile guppies from upper and lower courses show an equally strong shoaling tendency (Magurran and Seghers 1990); this is likely because juveniles face a similar threat of predation from adult guppies across populations.

In contrast to predation, parasitism is poorly characterized in Trinidadian guppy populations, but smallscale studies provide us with clear predictions to test on a larger scale. The dominant guppy parasites, which include Gyrodactylus turnbulli and G. bullatarudis (hereafter Gyrodactylus) are directly transmitted ectoparasitic monogeneans that impact guppy swimming ability (Cable and Harris 2002), reproductive fitness (e.g., Kennedy et al. 1987), and survival (van Oosterhout et al. 2007). Shoaling is an important anti-predator behavioral trait in guppies that facilitates Gyrodactylus transmission (Richards et al. 2010, Croft et al. 2011, Johnson et al. 2011), and females are more likely to become infected than males because of their higher shoaling tendency (Richards et al. 2010, Johnson et al. 2011). Notably, Johnson et al. (2011) found that Gyrodactylus transmission remained high in aquaria with reduced guppy density, indicating that social interactions were more important than density in maintaining transmission rates. The few field studies describing this parasite-host-predator system have also indicated its suitability for investigating sex-specific trait-mediated indirect effects. As we would predict from the small-scale studies, Gyrodactylus prevalence tends to be greater in populations in the lower courses of rivers in Trinidad, where guppies shoal more, although this is not always the case (Martin and Johnsen 2007, Fraser and Neff 2010, Gotanda et al. 2013). Additionally, prevalence may differ between males and females depending on the course of the river (Gotanda et al. 2013), but some studies have found no sex difference in infection (Martin and Johnsen 2007, Fraser and Neff 2010), despite sex differences in shoaling behavior.

Rather than asking how parasites contribute to patterns already recognized as driven by predators in this system (e.g., body size and coloration: Gotanda et al. 2013), we build on previous work by asking how this predator-driven spatial pattern in guppy traits indirectly affects Gyrodactylus parasite prevalence. Specifically, we test the prediction that populations that experience higher predation pressure will show greater parasite prevalence. Furthermore, we expect prevalence among females to be higher than among males, especially in populations that experience higher predation pressure, given that they shoal more than males. Because juveniles face similar levels of predation pressure across populations, we predict parasitism among juveniles to be relatively consistent. We additionally test whether the level of inter-site variation could explain the apparently contradictory results in previous guppy-gyrodactylid field surveys, and test for temporal patterns in parasite prevalence. We use extensive field sampling to test these predictions. A multi-model inference and model-averaging approach to data analysis suits data sets like ours 
that contain a large number of explanatory variables, because it takes into account model uncertainty and can provide better estimates of model parameters than more traditional null hypothesis significance tests (Bolker et al. 2009, Grueber et al. 2011).

\section{Methods \\ Data collection}

We collected 4715 guppies from 62 sites in Trinidad between 2003 and 2009 (Appendix A: Table A1). Whole shoals were enclosed in the river by a net, and individual fish were scooped out of the water using small buckets to avoid dislodging ectoparasites. Fish standard length, mass, and class (female, male, or juvenile) were recorded. We attempted to obtain equal numbers of each sex at each site. The fish were killed on site with an overdose of $0.02 \%$ tricaine methanesulfonate (MS222; Pharmaq, Fordingbridge, UK) and preserved individually in $90 \%$ molecular grade ethanol. All fish, and the ethanol in which they had been transported, were then examined using a stereomicroscope with fiber-optic illumination for any externally visible symbionts. It is unknown whether organisms such as Trichodina and Apiosoma cause any harm to their hosts, and we therefore collectively refer to these and other potential guppy parasites as symbionts. Gyrodactylus spp., Trichodina spp., Ichthyophthirius spp., Apiosoma spp., digenean metacercariae, Camallanus spp., and fungal infections were recorded; no other taxa were found. For Gyrodactylus spp. (hereafter Gyrodactylus), we did not identify the worms to species level, and acknowledge that there are at least two species that infect guppies ( $G$. turnbulli and $G$. bullatarudis). We recorded the number of Gyrodactylus worms present but only the presence of other symbionts because of difficulties in quantification. Throughout, we define prevalence as the proportion of fish that was infected, Gyrodactylus mean intensity as the average number of worms carried by the infected fish in a population, and mean abundance as the average number of worms carried by all fish in a population (Bush et al. 1997).

\section{Data analysis}

To test for the factors important in Gyrodactylus infection, we constructed models using both Gyrodactylus presence ( 0 or 1 ) and Gyrodactylus count (number of parasites) on each fish as the response variables. Note that Gyrodactylus presence is used to estimate prevalence, whereas the count is used to calculate mean abundance (sensu Bush et al. 1997). Here, we describe the presence model (i.e., prevalence) because it shows the best fit to the data. This discrepancy in our ability to explain prevalence and abundance in these populations is unsurprising; parasite abundance is more dependent than prevalence on host infection history, susceptibility, and immune response, all of which are beyond the scope of our data. We do, however, give the results from the Gyrodactylus count model (i.e., abundance) in Appen- dices A (Tables A2 and A3) and B (Figs. B1 and B2). All statistical analyses were conducted using $\mathrm{R}$ statistical software (v. 3.0.2; R Core Team 2013), and script and data files are provided in the Supplement.

Throughout the analyses, we used the watercourse (course) the fish were sampled from (i.e., lower, mid, upper sections of the river or Pitch Lake [hereafter lake]) as a proxy for the predation regime faced by guppies at each site. The lake should also be considered separately from the rivers because of the unique properties of pitch water; this has been found to protect guppies from Gyrodactylus infection (Schelkle et al. 2012). During sampling, we recorded the presence of fish species known to predate upon guppies, including Anablepsoides hartii, Aequidens pulcher, Cichlasoma taenia, Polycentrus schomburgkii, Crenichla alta, Hoplias malabaricus, and Gobiomorous dormitor. Presence of predatory species is a recognized measure of predation pressure in this system (Seghers 1974, Reznick and Endler 1982, Magurran and Seghers 1994b, Reznick et al. 1997). To confirm that our course variable, which reflected the location of the site within the rivers or lake, was correlated with predator fauna, we calculated the species richness of the major guppy predators ( $P$. schomburgkii, C. alta, H. malabaricus, and $G$. dormitor) at each site. Each of these species has a trophic level of greater than 3.5 (Fishbase). ${ }^{5}$ This indicates that they are generally ichthyophagous (Magurran 2005). We used ANOVA to test for differences in major guppy predator species richness between sites in each of our four categories. Sites categorized as upper had significantly lower mean predatory species richness than those categorized as mid, lower, or lake (Appendix B: Fig. B3; $\left.F_{3,54}=9.143, P<0.001\right)$. Overall, therefore, the levels of our course variable differed significantly in mean predator species richness, but there was variation between sites within each course. Consequently, we used the course variable in further models rather than predator species richness because the latter is less accurate; we may have missed the predators at some sites, and they may move between sites within the course. Additionally, the course variable reflects the presence of waterfall migration barriers and, hence, which sites these predators could access. Guppy traits driven by predation pressure, such as shoaling, change over evolutionary time (Endler 1980, Reznick et al. 1997, Gordon et al. 2009), and are therefore not dependent on the presence of predators on our sampling day. In summary, the overall difference in predation pressure between courses, confirmed by our own predator species richness score, more accurately represents the predator-driven traits of the guppies in our sample.

\section{Analysis of Gyrodactylus presence}

We used the presence or absence of Gyrodactylus parasites on guppies as the categorical response variable

\footnotetext{
${ }^{5}$ www.fish-base.org
} 
TABLE 1. The top-ranked candidate models explaining variation in Gyrodactylus spp. infection of guppies.

\begin{tabular}{lccccc}
\hline \hline \multicolumn{1}{c}{ Model } & df & Log-likelihood ratio & AIC & $\Delta$ AIC & AIC weight \\
\hline $2,3,4,5,7,8,9$ & 21 & -1870.15 & 3782.30 & 0.00 & 0.54 \\
$1,2,3,4,5,7,8,9$ & 22 & -1870.15 & 3784.30 & 2.00 & 0.20 \\
$2,3,4,5,8,9$ & 15 & -1877.25 & 3784.49 & 2.10 & 0.18 \\
$1,2,3,4,5,6,7,8,9$ & 24 & -1869.02 & 3786.04 & 3.74 & 0.08 \\
\hline
\end{tabular}

Notes: AIC stands for Akaike information criteria. The model terms are coded as follows: 1 , presence of Trichodina spp.; 2, course; 3, class; 4, year; 5, mass; 6, presence of Trichodina-class; 7, course-class; 8, course-mass; 9, class-mass.

in a binomial generalized linear mixed model (GLMM). The starting model included year, class (female, male, or juvenile guppy), course (upper, mid, lower, or lake), and fish mass as fixed main effects. The following two-way interactions between these factors were included: course-class, course-mass, and class-mass. The prevalence of other symbionts in our sample was low (Trichodina $\mathrm{spp} .=0.061 ;$ Ichthyophthirius $\mathrm{spp} .=0.010$; Apiosoma spp. $=0.004$; digenean metacercariae $=0.006$; Camallanus spp. $=0.0004$; fungal infection $=0.007$ ). We therefore only included the presence of Trichodina spp., the most common symbiont after Gyrodactylus in our sample, and its interaction with host class, as explanatory variables in the Gyrodactylus presence model. We sampled only 14 sites on more than one occasion (Appendix A: Table A1; Appendix B: Fig. B4), and as the full model contained site as part of the random effect, it was not possible to include the year-course interaction in this full model.

During simplification of the starting model, it became clear that there were several, equally well-supported models based on comparisons of Akaike's Information Criterion (AIC) and $R^{2}$ (calculated using the method given by Nakagawa and Schielzeth [2013]). In order to take into account model uncertainty, and to increase the robustness of the parameter estimates and assess their relative importance, we employed an informationtheoretic approach to multi-model inference (Burnham and Anderson 2002, Grueber et al. 2011).

Following Grueber et al. (2011), we constructed a global model using the lme4 package (Bates et al. 2013) in R with all fixed terms included about which we had a priori hypotheses, namely all of those in the starting model. We then standardized the model parameters to a mean of 0 and a standard deviation of 0.5 using the arm package (Gelman and $\mathrm{Su} 2013$ ). We used the zero method of parameter weighting because we were interested in an estimate of the effect that each of our parameters had on prevalence, rather than the effect of one particular parameter (Burnham and Anderson 2002, Nakagawa and Freckleton 2011). Using the dredge function in the MuMIn package (Bartón 2013), we created a set of models, and from these, selected those within the top four $\triangle \mathrm{AIC}(n=4)$. We used $\mathrm{AIC}$, rather than $\mathrm{AIC}_{\mathrm{c}}$, because the number of observations was more than 40 times the number of explanatory variables in our starting model (Burnham and Anderson 2002). The model.avg function then produced averaged parameter estimates from this top set of models, and the relative importance of these parameters. The relative importance of each parameter was calculated by summing the Akaike weights across all the models in which the parameter occurred (Burnham and Anderson 2002). We had some issues with non-convergence of the model (Grueber et al. 2011): the confidence intervals for the estimates for 2008 and 2009 were very large, probably because of the relatively small sample sizes for these years ( $n=192$ and 111 respectively). Rerunning the model excluding these two years improved the convergence and did not change the conclusions (remaining $n=4412$ ).

The sampling was conducted over different spatial scales. This was incorporated into the model as a hierarchical random factor; sample site was nested within course, nested within river, nested within drainage. During model simplification, we used likelihood ratio tests to examine the importance of each level of this nested term. We included these factors as random terms because we wanted to be able to generalize these results to other sites across other rivers.

\section{RESULTS \\ Gyrodactylus presence: fixed effects}

The second-order interactions between course, year, host class, and mass proved to be important predictors of Gyrodactylus infection (Tables 1 and 2). Our data confirmed the pattern that Gyrodactylus prevalence is higher in the lower courses of rivers in this system (course, Table 1; Martin and Johnsen 2007, Gotanda et al. 2013), and demonstrated a difference in this pattern between males, females, and juveniles (course-class; Fig. 1). Prevalence among juveniles did not change between courses of the river. For females and males, however, there was a marked difference in prevalence between the courses. Prevalence was higher in females than in males in the lower course, but this difference became less and less evident through courses with decreasing overall prevalence. These patterns were not evident in the Gyrodactylus abundance data (Appendix B: Fig. B1).

In upper-course guppies, prevalence of Gyrodactylus increased with mass for juvenile but not adult guppies, whereas in lower-course guppies, mass was an important predictor of Gyrodactylus prevalence across all three guppy classes (course-mass and class-mass, Table 2; Fig. 2). 
TABLE 2. Model-averaged standardized coefficients, unconditional standard error, and $95 \%$ confidence intervals of predictors for guppy infection with Gyrodactylus spp.

\begin{tabular}{|c|c|c|c|c|c|}
\hline \multirow[b]{2}{*}{ Predictor } & \multirow{2}{*}{$\begin{array}{l}\text { Standardized } \\
\text { coefficient }\end{array}$} & \multirow{2}{*}{$\begin{array}{l}\text { Unconditional } \\
\text { SE }\end{array}$} & \multicolumn{2}{|c|}{$95 \% \mathrm{CI}$} & \multirow{2}{*}{$\begin{array}{l}\text { Relative importance } \\
\text { of overall predictor }\end{array}$} \\
\hline & & & $2.5 \%$ & $97.5 \%$ & \\
\hline Intercept $\dagger$ & -4.303 & 1.896 & -8.021 & -0.587 & \\
\hline Course & & & & & 1 \\
\hline Lower & 2.274 & 1.968 & -1.583 & 6.132 & \\
\hline Mid & 0.424 & 2.173 & -3.835 & 4.684 & \\
\hline Upper & 1.543 & 1.990 & -2.358 & 5.444 & \\
\hline Class & & & & & 1 \\
\hline $\mathrm{j}$ & 2.204 & 1.477 & -0.691 & 5.099 & \\
\hline $\mathrm{m}$ & 0.161 & 0.632 & -1.078 & 1.399 & \\
\hline Year & & & & & 1 \\
\hline 2004 & 0.177 & 0.144 & -0.106 & 0.460 & \\
\hline $2006 \dagger$ & 1.903 & 0.169 & 1.572 & 2.234 & \\
\hline Mass & 1.640 & 0.853 & -0.033 & 3.312 & 1 \\
\hline Course-class & & & & & 1 \\
\hline Lower-j† & -2.887 & 1.045 & -4.935 & -0.838 & \\
\hline Mid-j† & -4.719 & 1.373 & -7.409 & -2.028 & \\
\hline Upper-j $\dagger$ & -2.967 & 1.050 & -5.024 & -0.910 & \\
\hline Lower-m & -0.266 & 0.691 & -1.620 & 1.089 & \\
\hline Mid-m & -0.763 & 0.910 & -2.546 & 1.020 & \\
\hline Upper-m & -0.539 & 0.698 & -1.908 & 0.830 & \\
\hline Course-mass & & & & & 1 \\
\hline Lower-mass & -0.848 & 0.862 & -2.537 & 0.841 & \\
\hline Mid-mass & -1.310 & 1.094 & -3.453 & 0.834 & \\
\hline Upper-mass & -1.603 & 0.879 & -3.327 & 0.120 & \\
\hline Class-mass & & & & & 0.82 \\
\hline j-mass $\dagger$ & 2.812 & 0.629 & 1.580 & 4.044 & \\
\hline $\mathrm{m}$-mass & 0.759 & 0.395 & -0.015 & 1.532 & \\
\hline Trichodina & -0.014 & 0.278 & -0.559 & 0.531 & 0.28 \\
\hline Class-trichodina & & & & & 0.08 \\
\hline j-trichodina & -1.246 & 1.077 & -3.357 & 0.865 & \\
\hline m-trichodina & 0.244 & 0.387 & -0.515 & 1.003 & \\
\hline
\end{tabular}

Notes: Class refers to host class (male, $\mathrm{m}$, or juvenile, $\mathrm{j}$ ); trichodina refers to the presence of Trichodina spp. Upper, lower, and mid refer to the upper, lower, and middle courses of the rivers sampled in Trinidad.

$\uparrow$ Confidence intervals for these predictors do not include zero.

Our data revealed a temporal change in the prevalence of Gyrodactylus parasites (year, Table 2; Fig. 3). To test whether this was an artifact of the sites sampled in these years, and therefore represented a spatial rather than temporal change in prevalence, we plotted the change in prevalence between the first and second visit to each site that was visited more than once (Appendix B: Fig. B4). The pattern observed in the overall data (Fig. 3) was also present, though nonsignificant, in the lower sites in this subset $(n=7$; mean change in prevalence $[95 \%$ confidence limits $]=0.174[-0.10,0.45])$.

We used a subset of the data (data from lower- and upper-course populations only) to run two additional GLMs including the year-course interaction as post-hoc tests. The response variable for one model was the mean prevalence from each sample site (using a quasi-Poisson error family and a log-link function), and for the other we used data from the individual fish (binomial error family). These tests revealed that, although there was a strong year effect across both site and individual level analyses (site, $F_{3,64}=3.061, P=0.034$; individual, deviance $=151.25, \mathrm{df}=3,4177, P<0.001)$, the yearcourse interaction was only significant in the individual level analysis (deviance $=183.27$, $\mathrm{df}=7,4177, P<$ 0.001 ; Fig. 3). Here, deviance is analogous to the $F$ statistic. From our data, therefore, we can say that Gyrodactylus prevalence increased through time, and that there was a suggestion that this increase happened faster at lower- than upper-course sites.

\section{Gyrodactylus presence: random effects}

The prevalence of Gyrodactylus was highly spatially variable, and most variation (61\%) occurred between sample sites, i.e., on the smallest spatial scale. In contrast, differences between drainages, between rivers within drainages, and between courses within rivers did not significantly contribute to differences in prevalence (Appendix B: Fig. B5), and these factors were all removed from the random model (following Bolker et al. 2009). Comparison of the AIC values between models with and without each of these nested random terms confirmed that the model containing just sample site as a 


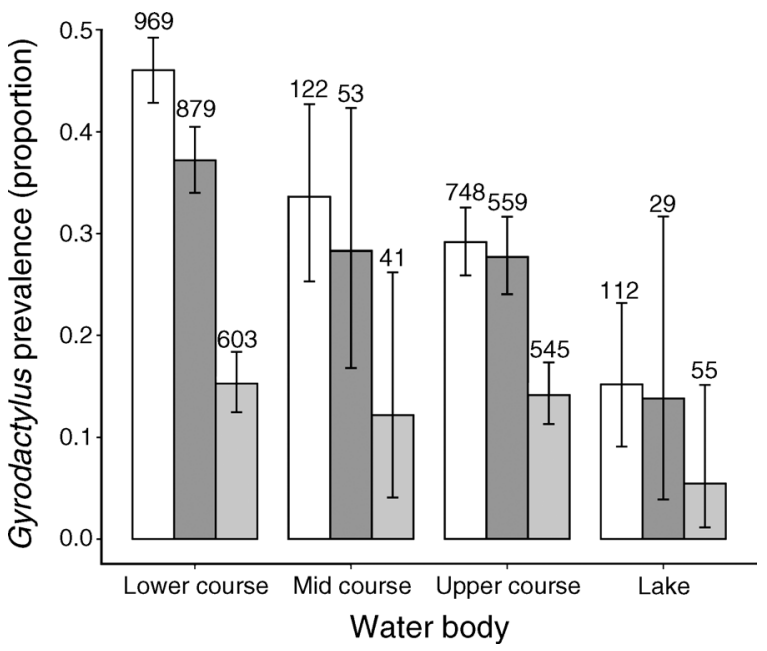

FIG. 1. Mean Gyrodactylus spp. prevalence in Trinidadian guppy (Poecilia reticulata) (the proportion of fish that were infected with the parasite) from the lower, mid, and upper courses of the rivers sampled, and Pitch Lake (Lake), Trinidad. White bars are data from female fish, dark gray from male fish, and light gray from juvenile fish. Error bars show the $95 \%$ confidence intervals; these were calculated following the Clopper-Pearson or "exact" method for binomial distributions. The numbers above the bars give the total number of fish sampled for that characteristic (i.e., 969 female fish were sampled from the lower river courses).

random term was superior: it had the lowest AIC. The global model for the model averaging therefore included the simplified random term (site).

\section{Discussion}

Our results show that Gyrodactylus infection in guppies is age- and sex-specific, and that there is significant spatiotemporal variation between Trinida-

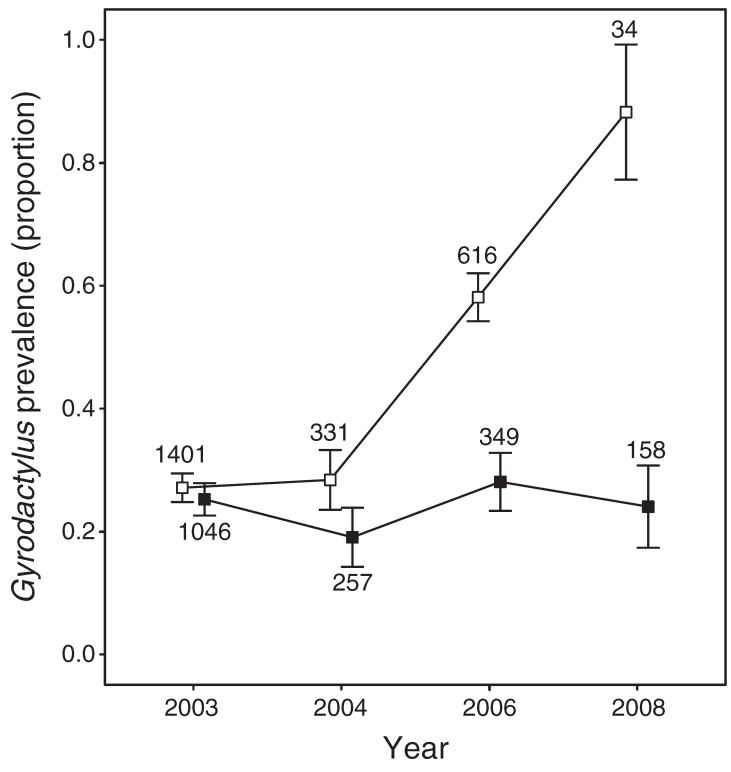

FIG. 3. Change in mean Gyrodactylus spp. prevalence over the years sampled in this study. White squares represent data from fish from lower-course sites and black squares fish from the upper. The data are the means from all fish sampled and the error bars are the $95 \%$ confidence intervals around those means. These were calculated following the Clopper-Pearson method for binomial distributions. Numbers listed along squares give the overall number of fish contributing to each data point.

dian populations. Gyrodactylus prevalence was higher among females than males, but only in fish from the lower courses (i.e., high-predation sites) of the 26 rivers sampled (Fig. 1). There was no difference in prevalence among juveniles from different courses (lower, mid, upper, or lake; Fig. 1). These findings support the role of age- and sex-specific trait-mediated indirect effects of
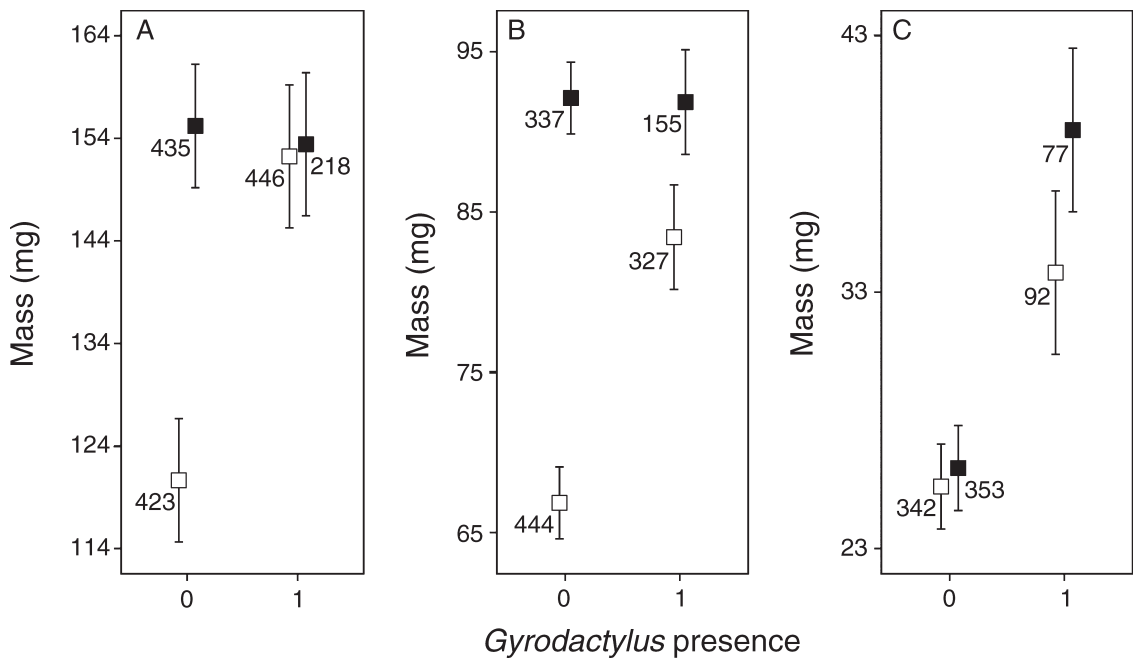

FIG. 2. The relationship between fish mass and Gyrodactylus presence in (A) females, (B) males, and (C) juveniles across the lower and upper courses. Presence is measured as 1 , absence as 0 . These data are from sites where at least one fish was infected with Gyrodactylus. The white squares represent data from lower-course, the black upper-course sites. Error bars are the $95 \%$ confidence intervals, and the numbers to the left of the squares give the total number of fish that contributed to each data point. 
predators on infection prevalence in their guppy prey. Although our results are correlational, we interpret them in light of a vast number of experimental studies on this system to draw conclusions about the factors driving parasite prevalence on guppies in the natural environment in Trinidad.

Gyrodactylus prevalence was higher in females than in males but only in the lower courses of the rivers; there are several, non-mutually exclusive explanations for this pattern. Host shoaling behavior is important for parasite transmission (Richards et al. 2010, Croft et al. 2011), and females tend to shoal more than males because males trade off the advantages of schooling against the search for mating opportunities (Magurran and Seghers 1994b, Griffiths and Magurran 1998). This sex difference is due to the fact that female reproductive fitness is dependent on survival and longevity; male guppies, by contrast, can sire offspring up to 10 months post mortem (Lopez-Sepulcre et al. 2013) and consequently spend more time harassing females than engaging in anti-predator behavior (Magurran and Seghers 1994b). The relatively higher parasite prevalence of females observed only in the lower courses is consistent with the fact that shoaling is more common in downstream populations, due to increased predation pressure (Seghers 1974, Endler 1978). Laboratory studies also confirm that the frequency of social contact governs Gyrodactylus epidemics and that the more gregarious female guppies contract infections sooner than the more solitary males (Johnson et al. 2011).

Further support for the role of predator-driven traitmediated indirect effects on parasite prevalence comes from the unchanging prevalence among juveniles across the lower, mid, and upper courses. Juvenile guppies from upper- and lower-course populations face equal predation pressure from adult guppies and show equally strong shoaling tendencies in both habitats (Magurran and Seghers 1990). This suggests that there is no difference in the rate of parasite transmission among juveniles of the upper-, mid-, and lower-course populations, which would explain why they show similar parasite prevalence across habitats.

Our results indicate the importance of exposure, rather than susceptibility, to parasites in this system. Two lines of evidence suggest that guppies from lowpredation populations are less resistant to Gyrodactylus infection than those from high-predation populations. First, laboratory infections reveal that upper Aripo river (low predation) guppies have lower innate resistance to Gyrodactylus than lower Aripo guppies (high predation; Cable and van Oosterhout 2007b). Secondly, guppies from low-predation populations have higher cortisol levels than those from high-predation populations (Fischer et al. 2014), and higher cortisol levels are associated with lower Gyrodactylus resistance in salmonids (Harris et al. 2000). Despite guppies from highpredation populations therefore likely being more resistant, Gyrodactylus prevalence was higher among them; this is most probably due to the increased transmission potential at these sites.

Pitch Lake provides an interesting exception to the pattern we observed elsewhere; although guppies here experience relatively high levels of predation pressure, Gyrodactylus prevalence was low and uniform across males, females, and juveniles. A previous study has, however, described the anthelminthic properties of pitch water (Schelkle et al. 2012), and this might bring Gyrodactylus prevalence in the lake below the threshold necessary for it to be noticeably affected by guppy response to predation pressure.

Infection probability was positively correlated with the size of guppies, but this correlation was only observed in the lower courses (Fig. 2). Laboratory experiments and computational modeling show that parasite load and the duration of infection increases with increased host size (van Oosterhout et al. 2003, 2008, Cable and van Oosterhout 2007a), and this may result in the positive correlation between body size and infection incidence observed in the lower courses. Catch bias may also be important; larger fish are likely to be able to support parasites with less of a decrease in condition than smaller fish (Krause et al. 1998), which in turn will improve their chance of survival (and of being observed). However, the pattern of infected fish being larger than uninfected fish does not hold for adults in the upper-course populations. Parasite infection will not increase predation risk in these upper courses; infected fish are more likely to survive and clear their infection. Furthermore, given that shoaling increases the probability of contracting an infection, lower-course guppies are more likely to become reinfected as they grow. Upper-course guppies, by contrast, are less likely to become reinfected once they clear an infection because of their more solitary lifestyle and the lower overall prevalence in these populations. The correlation between size and infection probability is the same across habitats for juveniles. Because juveniles show similar shoaling behavior in the upper and lower courses, the probability of acquiring an infection increases with increased size (and age) at similar rates across habitats.

Age- and sex-specific predator-driven trait-mediated indirect effects provide the most parsimonious and wellsupported explanation for our results, but the patterns may be partially explained by other processes. First, parasite infection may lead to increased predation risk (Hatcher et al. 2006, Johnson et al. 2006); if Gyrodactylus-infected fish are predated more frequently, and predation is more severe on males than on females, this would explain why we recorded a lower proportion of infected males than infected females. There is no empirical test of parasite-induced vulnerability to predation in this system, but we can infer that males might be more at risk than females. Males of many species across taxa are less resistant to and less tolerant of infection (Zuk and McKean 1996). Indeed, Gyrodactylus infection makes male guppies, but not females, 
more likely to be swept downstream in flood conditions (van Oosterhout et al. 2007), despite no consistent difference in either Gyrodactylus resistance or tolerance between the sexes during laboratory infections (e.g., van Oosterhout et al. 2003, Cable and van Oosterhout $2007 a$ ). In the wild, therefore, males may be more affected by infection than females, potentially making them more vulnerable to predation.

A further role for predators in our observed pattern could be as paratenic hosts for the parasites. Gyrodactylus infections were found on a number of Anablepsoides hartii from sites sampled in this study (Cable et al. 2013). Experimental infections demonstrate that the parasites can survive on $A$. hartii and transfer from them to guppies in seminatural conditions (Cable et al. 2013). However, whether Gyrodactylus can use other predatory species in the same manner is unknown. Given that the population size of guppies tends to be considerably higher than that of their predators, we do not think that presence of other paratenic hosts will have important implications for guppy-Gyrodactylus dynamics.

Differences in guppy density or sex ratio between sites could influence the patterns we describe. One of the challenges in this field is to ascribe observed patterns to trait- rather than density-mediated indirect effects (Raffel et al. 2010). Extensive work on this system has shown, however, that guppy populations do not differ consistently in density or sex ratio, neither spatially nor temporally (Pettersson et al. 2004, Magurran 2005). Coupled with the boom and bust infection trajectories on fish in the laboratory (Cable and van Oosterhout 2007a), these factors may dramatically alter parasite prevalence and intensity rapidly and across small spatial scales. Any density-mediated indirect effects on parasitism are therefore likely to be transient and would not contribute to the large-scale pattern we observed. Differences in predation level, on the other hand, are consistent both spatially and temporally and drive adaptive evolutionary responses in the host, such as shoaling (Houde 1997, Reznick et al. 1997, Magurran 2005). Additionally, the rate of Gyrodactylus transmission is not density dependent, but is governed by the frequency of social contacts, i.e., shoaling (Johnson et al. 2011). The consistent differences in parasite prevalence between populations that experience different predation pressure are thus more likely to be trait- than densitymediated.

Density-mediated effects might be important, however, on a small spatial scale. We found that variation in the prevalence and abundance of Gyrodactylus spp. infection was greatest at the smallest scale, i.e., between the 62 individual sample sites, and this variation exceeded the differences that existed between courses, rivers, and drainages (Appendix B: Fig. B5). The typical guppy researcher's methodology of taking one lowercourse and one upper-course sample per river (van Oosterhout et al. 2006, Martin and Johnsen 2007, Fraser and Neff 2010, Gotanda et al. 2013) is therefore likely to miss important sources of variation. This variability also explains previous findings from smaller-scale field surveys that contradict the present study, such as the apparent absence of sex differences in Gyrodactylus infection in wild guppies (Martin and Johnsen 2007, Fraser and Neff 2010 cf. Gotanda et al. 2013).

The probability of gyrodactylid infection in guppies increased over the seven years sampled and this increase appears to have happened more quickly in the lower than upper courses of the rivers (Fig. 3; Appendix B: Fig. B2). Other studies of temporal change in this system only sampled across two consecutive years (Fraser et al. 2010, Gotanda et al. 2013), and therefore could not detect this pattern. Clearly, many of the factors important in determining spatial variation also apply to the temporal pattern, and because we resampled so few sites $(n=14)$, our ability to discriminate between temporal and spatial explanations for this pattern is limited. Because the temporal effect was so important in our models, however, we feel obliged to suggest a potential explanation for this pattern. River temperature is closely linked to canopy cover, although air temperatures recorded at Trinidad's Piarco Airport do not show an increase over the study period. ${ }^{6}$ Due to Trinidad's rapid urbanization (Magurran 2005), canopy cover in the lowland sites is likely to have decreased, which in turn may have raised water temperatures. Moderate increases in temperature lead to faster parasite population growth rate in laboratory studies (Scott and Nokes 1984), which could have contributed to the observed temporal pattern in the downstream populations.

\section{Conclusions}

Trait-mediated indirect effects are unlikely to act homogenously across all individuals in a population due to sex-specific differences and allometric variation between life stages. The most parsimonious explanation of our results is that predators induce age- and sexspecific trait-mediated indirect effects on the probability of parasitism by Gyrodactylus. Although the importance of trait-mediated indirect effects in community structure and predator-prey interactions is gaining appreciation (Raffel et al. 2010), that these effects can act differently on individuals within the same species has not previously been demonstrated. The sex-specific action of these effects is perhaps particularly relevant to parasite ecology because of the well-established sex difference in parasitism and transmission rates (Zuk and McKean 1996). The difference we observe in parasite prevalence between males, females, and juveniles in populations subjected to different predation pressures is, we believe, the first example of age- and sex-specific trait-mediated effects of predation on parasite prevalence in a natural system.

\footnotetext{
${ }^{6} \mathrm{http}: / /$ www.tutiempo.net/
} 


\section{ACKNOWLEDGMENTS}

We thank G. A. Archard, N. Barson, H. Hansen, M. McMullan, and B. Schelkle for assistance with fieldwork, R. Thomas for help with the analysis, and K. Young, and the anonymous reviewers for helpful comments on earlier versions of the manuscript. This work was funded by: the Fisheries Society of the British Isles (FSBI PhD studentship to J. F. Stephenson); the Natural Environment Research Council, UK (advanced fellowship to J. Cable; NER/J/S/2002/00706); and ELSA, the Earth and Life Systems Alliance (C. Van Oosterhout).

\section{Literature Cited}

Anderson, R. M., and R. M. May. 1981. The population dynamics of microparasites and their invertebrate hosts. Philosophical Transactions of the Royal Society B 291:451524.

Bartón, K. 2013. MuMIn: multi-model inference package. Package version 1.9. http://cran.r-project.org/web/packages/ MuMIn/index.html

Bates, D., M. Maechler, and B. Bolker. 2013. lme4: linear mixed-effects models using $\mathrm{S} 4$ classes. $\mathrm{R}$ package version 0.999999-0. http://CRAN.R-project.org/package=lme4

Bolker, B., M. E. Brooks, C. J. Clark, S. W. Geange, J. R. Poulsen, M. H. H. Stevens, and J. S. S. White. 2009. Generalized linear mixed models: a practical guide for ecology and evolution. Trends in Ecology and Evolution 24:127-135.

Burnham, K. P., and D. R. Anderson. 2002. Model selection and multi-model inference: a practical information-theoretic approach. Second edition. Springer, New York, New York, USA.

Bush, A. O., K. D. Lafferty, J. M. Lotz, and A. W. Shostak. 1997. Parasitology meets ecology on its own terms: Margolis et al. revisited. Journal of Parasitology 85:575-583.

Cable, J., G. A. Archard, R. S. Mohammed, M. McMullan, J. F. Stephenson, H. Hansen, and C. van Oosterhout. 2013. Can parasites use predators to spread between primary hosts? Parasitology 140:1138-1143.

Cable, J., and P. D. Harris. 2002. Gyrodactylid developmental biology: historical review, current status and future trends. International Journal of Parasitology 32:255-280.

Cable, J., and C. van Oosterhout. 2007a. The impact of parasites on the life history evolution of guppies (Poecilia reticulata): the effects of host size on parasite virulence. International Journal for Parasitology 37:1449-1458.

Cable, J., and C. van Oosterhout. 2007b. The role of innate and acquired resistance in two natural populations of guppies (Poecilia reticulata) infected with the ectoparasite Gyrodactylus turnbulli. Biological Journal of the Linnean Society 90: 647-655.

Croft, D. P., M. Edenbrow, S. K. Darden, I. W. Ramnarine, C. van Oosterhout, and J. Cable. 2011. Effect of gyrodactylid ectoparasites on host behaviour and social network structure in guppies, Poecilia reticulata. Behavioral Ecology and Sociobiology 65:2219-2227.

Decaestecker, E., L. De Meester, and D. Ebert. 2002. In deep trouble: habitat selection constrained by multiple enemies in zooplankton. Proceedings of the National Academy of Sciences USA 99:5481-5485.

Duffy, M. A., J. M. Housley, R. M. Penczykowski, C. E. Cáceres, and S. R. Hall. 2011. Unhealthy herds: indirect effects of predators enhance two drivers of disease spread. Functional Ecology 25:945-953.

Endler, J. A. 1978. A predator's view of animal color patterns. Evolutionary Biology 11:319-364.

Endler, J. A. 1980. Natural selection on color patterns in Poecilia reticulata. Evolution 34:76-91.

Fischer, E. K., R. M. Harris, H. A. Hofmann, and K. L. Hoke. 2014. Predator exposure alters stress physiology in guppies across timescales. Hormones and Behavior 65:165-172.
Fraser, B. A., and B. D. Neff. 2010. Parasite mediated homogenizing selection at the MHC in guppies. Genetica 138:273-278.

Fraser, B. A., I. W. Ramnarine, and B. D. Neff. 2010. Temporal variation at the MHC class IIB in wild populations of the guppy (Poecilia reticulata). Evolution 64:2086-2096.

Gelman, A., and Y. S. Su. 2013. arm: data analysis using regression and multilevel/hierarchical models. Package version 1.6. http://cran.r-project.org/web/packages/arm/index. html

Gordon, S. P., D. N. Reznick, M. T. Kinnison, M. J. Bryant, D. J. Weese, K. Rasanen, N. P. Millar, and A. P. Hendry. 2009. Adaptive changes in life history and survival following a new guppy introduction. American Naturalist 174:34-45.

Gotanda, K. M., L. C. Delaire, J. A. M. Raeymaekers, F. Pérez-Jvostov, F. Dargent, P. Bentzen, M. E. Scott, G. F. Fussman, and A. P. Hendry. 2013. Adding parasites to the guppy-predation story: insights from field surveys. Oecologia 172:155-166.

Griffiths, S. W., and A. E. Magurran. 1998. Sex and schooling behaviour in the Trinidadian guppy. Animal Behaviour 56: 689-693.

Grueber, C. E., S. Nakagawa, R. J. Laws, and I. G. Jamieson. 2011. Multimodel inference in ecology and evolution: challenges and solutions. Journal of Evolutionary Biology 24:699-711.

Harris, P. D., A. Soleng, and T. A. Bakke. 2000. Increased susceptibility of salmonids to the monogenean Gyrodactylus salaris following administration of hydrocortisone acetate. Parasitology 120:57-64.

Haskins, C. P., E. F. Haskins, J. J. A. McLaughlin, and R. E. Hewitt. 1961. Polymorphism and population structure in Lebistes reticulata, an ecological study. Pages 320-395 in W. F. Blair, editor. Vertebrate speciation, a University of Texas symposium. University of Texas Press, Austin, Texas, USA.

Hatcher, M. J., J. T. A. Dick, and A. M. Dunn. 2006. How parasites affect interactions between competitors and predators. Ecology Letters 9:1253-1271.

Holt, R. D., and M. Roy. 2007. Predation can increase the prevalence of infectious disease. American Naturalist 169: 690-699.

Houde, A. 1997. Sex, color and mate choice in guppies. Princeton University Press, Princeton, New Jersey, USA.

Johnson, M. B., K. D. Lafferty, C. van Oosterhout, and J. Cable. 2011. Parasite transmission in social interacting hosts: monogenean epidemics in guppies. PLoS ONE 6:e22634.

Johnson, P. T. J., D. E. Stanton, E. R. Preu, K. J. Forshay, and S. R. Carpenter. 2006. Dining on disease: how interactions between infection and environment affect predation risk. Ecology 87:1973-1980.

Kennedy, C. E. J., J. A. Endler, S. L. Poynton, and H. McMinn. 1987. Parasite load predicts mate choice in guppies. Behavioral Ecology and Sociobiology 21:291-295.

Krause, J., S. P. Loader, J. McDermott, and G. D. Ruxton. 1998. Refuge use by fish as a function of body length-related metabolic expenditure and predation risks. Proceedings of the Royal Society B 265:2373-2379.

Lopez-Sepulcre, A., S. P. Gordon, I. G. Paterson, P. Bentzen, and D. N. Reznick. 2013. Beyond lifetime reproductive success: the posthumous reproductive dynamics of male Trinidadian guppies. Proceedings of the Royal Society B 280: 20131116.

Magurran, A. E. 2005. Evolutionary ecology: the Trinidadian guppy. Oxford University Press, New York, New York, USA.

Magurran, A. E., and B. H. Seghers. 1990. Population differences in the schooling behaviour of newborn guppies, Poecilia reticulata. Ethology 84:334-342.

Magurran, A., and B. H. Seghers. 1994a. Predator inspection behaviour covaries with schooling tendency amongst wild 
guppy, Poecilia reticulata, populations in Trinidad. Behaviour 128:121-134.

Magurran, A. E., and B. H. Seghers. 1994b. Sexual conflict as a consequence of ecology: evidence from guppy, Poecilia reticulata, populations in Trinidad. Proceedings of the Royal Society B 255:31-36.

Martin, C. H., and S. Johnsen. 2007. A field test of the Hamilton-Zuk hypothesis in the Trinidadian guppy (Poecilia reticulata). Behavioral Ecology and Sociobiology 61:18971909.

McCoy, M. W., and B. M. Bolker. 2008. Trait-mediated interactions: influence of prey size, density and experience. Journal of Animal Ecology 77:478-486.

Nakagawa, S., and R. P. Freckleton. 2011. Model averaging, missing data and multiple imputation: a case study for behavioural ecology. Behavioral Ecology and Sociobiology 65:103-116.

Nakagawa, S., and H. Schielzeth. 2013. A general and simple method for obtaining $R^{2}$ from generalized linear mixedeffects models. Methods in Ecology and Evolution 4:133142.

Packer, C., R. D. Holt, P. J. Hudson, K. D. Lafferty, and A. P. Dobson. 2003. Keeping the herds healthy and alert implications of predator control for infectious disease. Ecology Letters 6:797-802.

Parris, M. J., and J. G. Beaudoin. 2004. Chytridiomycosis impacts predator-prey interactions in larval amphibian communities. Oecologia 140:626-632.

Pettersson, L. B., I. Ramnarine, S. A. Becher, R. Mahabir, and A. E. Magurran. 2004. Sex ratio dynamics and fluctuating selection pressures in natural populations of the Trinidadian guppy, Poecilia reticulata. Behavioral Ecology and Sociobiology 55:461-468.

R Core Team. 2013. R: A language and environment for statistical computing. R Foundation for Statistical Computing, Vienna, Austria. www.r-project.org

Raffel, T. R., J. T. Hoverman, N. T. Halstead, P. J. Michel, and J. R. Rohr. 2010. Parasitism in a community context: traitmediated interactions with competition and predation. Ecology 91:1900-1907.

Reznick, D. N., and J. Endler. 1982. The impact of predation on life history evolution in Trinidadian guppies (Poecilia reticulata). Evolution 36:160-177.

Reznick, D. N., F. H. Shaw, F. H. Rodd, and R. G. Shaw. 1997. Evaluation of the rate of evolution in natural populations of guppies (Poecilia reticulata). Science 275: 1934-1937.

Richards, E. L., C. van Oosterhout, and J. Cable. 2010. Sexspecific differences in shoaling affect parasite transmission in guppies. PLoS ONE 5:e13285.

Schelkle, B., R. S. Mohammed, M. P. Coogan, M. McMullan, E. L. Gillingham, C. van Oosterhout, and J. Cable. 2012. Parasites pitched against nature: Pitch Lake water protects guppies (Poecilia reticulata) from microbial and gyrodactylid infections. Parasitology 139:1772-1780.

Scott, M. E., and D. J. Nokes. 1984. Temperature-dependent reproduction and survival of Gyrodactylus bullatarudis (Monogenea) on guppies (Poecilia reticulata). Parasitology 89:221-228.

Seghers, B. H. 1974. Schooling behaviour in the guppy (Poecilia reticulata): an evolutionary response to predation. Evolution 28:486-489.

Stein, R. A., and J. J. Magnuson. 1976. Behavioral response of crayfish to a fish predator. Ecology 57:751-761.

van Oosterhout, C., P. D. Harris, and J. Cable. 2003. Marked variation in parasite resistance between two wild populations of the Trinidadian guppy, Poecilia reticulata (Pisces: Poeciliidae). Biological Journal of the Linnean Society 79:645-651.

van Oosterhout, C., D. Joyce, S. Cummings, J. Blais, N. Barson, I. Ramnarine, R. Mohammed, N. Persad, and J. Cable. 2006. Balancing selection, random genetic drift, and genetic variation at the major histocompatibility complex in two wild populations of guppies (Poecilia reticulata). Evolution 60:2562-2574.

van Oosterhout, C., R. S. Mohammed, H. Hansen, G. A. Archard, M. McMullan, D. J. Weese, and J. Cable. 2007. Selection by parasites in spate conditions in wild Trinidadian guppies (Poecilia reticulata). International Journal of Parasitology 37:805-812.

van Oosterhout, C., R. Potter, H. Wright, and J. Cable. 2008. Gyro-scope: an individual-based computer model to forecast gyrodactylid infections on fish hosts. International Journal for Parasitology 38:541-548.

Werner, E. E., and S. D. Peacor. 2003. A review of traitmediated indirect interactions in ecological communities. Ecology 84:1083-1100.

Zuk, M., and K. A. McKean. 1996. Sex differences in parasite infections: patterns and processes. International Journal for Parasitology 26:1009-1023.

\section{Supplemental Material}

\section{Ecological Archives}

Appendices A and B and the Supplement are available online: http://dx.doi.org/10.1890/14-0495.1.sm 